\title{
Optical Properties of Poly (vinyl alcohol) PVA Films Doped With Fe Citrate
}

\author{
Wasan A. Al-Taa'y \\ Department of Physics, College of Science, Al-Nahrain University, Baghdad-Iraq. \\ E-mail: wasanali )..@yahoo.com.
}

\begin{abstract}
Pure and Fe citrate doped poly (vinyl Alcohol) PVA films with different concentrations $(\cdot, \cdot, 0$, 1,0 , and $r$ ) wt $\%$ were prepared by using casting technique. Optical absorption measurements in the wavelength range $Y \cdots-\lambda \cdots n$ m were studied and confirmed that PVA films have an direct band gap that decreased from $0, \varepsilon \vee$ to $\varepsilon, \vee q \mathrm{eV}$ as the doping concentration increases to ${ }_{\mathrm{wt}} \%$. Optical constants such as absorption coefficient, refractive index, Extinction coefficient real and imaginary parts of dielectric constant have been studied; results show that the optical constants of the pure PVA films were increased after doping and with increasing impurity concentration. Urbach energy and optical conductivity were increases with the increasing of impurity concentration. The increase in the density of localized states $\mathrm{E}_{\mathrm{u}}$ from $\cdot, \leqslant 9$ to $\cdot, \bullet \leqslant \mathrm{eV}$ causes an expanding in the Urbach tail and consequently decreases the energy gap.
\end{abstract}

Keywords: PVA, Fe citrate, optical constants.

\section{Introduction}

Polymer solids have a great potential in many important applications due to their unique properties, such as low density, ability to form intricate shapes, versatile electric properties and low manufacturing cost. The wide range of polymer applications can be even more extended by incorporation of filler into polymer matrix, because dispersed filler may enhance various physical properties of the hostpolymer. The electrical and optical properties of selected polymer can be controllably modified owing to the type of the filler used, its concentration and the way in which itpenetrates and interacts with the chains of the polymer $[1, r]$.

Optical communications, including polymer optical fibers, optical waveguides and optical connectors have enormous applicationsdue to their ease of processing, relatively low cost and mass production compared to silica based optical materials. They also have potential advantages for applications in optical storage systems, such as high thermal stability, law absorption loss and the ability of refractive index changing upon exposure to light $\left[{ }^{\top}\right]$. Poly (vinyl alcohol) (PVA) is one of the most important polymeric materials as it has many applications in industry, It is a potential material having a very high dielectric strength, good change storage capacity and dopant- dependent electrical and optical properties and of course it is relativity low cost [ $\varepsilon$.

In recent years, studies on optical and electrical properties of polymer blend films have increased remarkably in view of their wide applications in radiation dosimetry and in optical and electronic devices $\left[{ }^{\circ}\right.$ ]. Investigation on the influence of sodium zirconate nanoparticles on the structural characteristics and electrical properties of polyvinyl alcohol nanocomposite films [־]. used ammonium dichromate doped PVA thin films to studied the refractive index and transmissions of the doped films have been measured $\left[{ }^{\vee}\right]$. Optical properties of pure and iron- doped cellulose acetate (CA) were investigated in the ( $r \cdots$ $\vee \cdots) \mu \mathrm{m}$ wavelength region $[\wedge]$ and the polymers PVA and PMMA were used to fabricate waveguides and photonic integrated circuits by doped with $\mathrm{TiO} r, \mathrm{ZrO} r$ or $\mathrm{CuO}$ [ ${ }^{9}$ ].

In this work optical constant of pure and Fecitratedoped PVA film shave been studied in wavelength range $(\uparrow \ldots . \wedge . \cdot)$ nmas a function of photon energy.

\section{Method Experimental Work}

Polyvinyl alcohol PVA of molecular weight $1 \cdots \mathrm{g} / \mathrm{mol}$ as a matrix element supplied by (BDH chemicals) with high purity and different weight percent of $\mathrm{Fe}$ citrate impurity $(\cdot, \cdot, 0,1,0$, and $r) \mathrm{wt} \%$ for 
samples (a, b, c, and d) respectively were dissolved in distilled water and with stirring the solution for about $(1 \cdot \min )$ at $\left(\wedge \cdot{ }^{\circ} \mathrm{C}\right)$ for complete dissolution. Poured the solution into a cleaned glass plate and kept till dried ( $₹$ days) at room temperature. The thickness of the produced films was in the range $(\wedge \cdot-10 \cdot) \mu \mathrm{m}$.

The optical constants of all films with and without $\mathrm{Fe}$ citrate impurity such as absorption coefficient, refractive index, extinction coefficient, real and imaginary parts of dielectric constant,energy gap, Urbach energy and optical conductivity was measured in the wavelength rang $(\uparrow \cdots, \wedge \cdots)$ nm by using UV-Visible spectrophotometer industrialize from (shimadzu UV-1 1.1 PC).

\section{Results and Discussion}

Optical absorbance measurements were taken for Fe citrate-poly vinyl alcohol samples to compare the effect of the filler particles on the optical properties of the composites. The optical properties of the films by means of the optical absorption in the UV-Vis region of $(Y \cdot-\wedge \cdot \cdot) \mathrm{nm}$ have been investigated. However the absorption, transmission and reflection measurements are limited to wavelengths at which the sample has an all measuring parameters. The absorption coefficient $\alpha$ was calculated from the absorbance A by using the following equation $[1 \cdot]$.

$$
\alpha=\frac{2.303 A}{x}
$$

Where: $x$ is the film thickness, $\mathrm{A}$ is the absorbance.

Fig. (1): shows the variation of absorption coefficient $\alpha$ with photon energy for the pure and doped PVA films with different concentration of $\mathrm{Fe}$ citrate $(\cdot, \cdot, 0,1,0$, and r)\% for samples (a, b, c, and d) respectively.
In this figure an obvious increase in the absorption coefficient with increasing photon energy was observed for sample (a) which may be attributed to the electronic transition from the bonding molecular orbit to nonbonding molecular orbit as indicated by Abd Al-Kader [ 11 ]. Doped samples (b, c, and d) shows a continues high increasing in the absorption coefficient with increasing photon energy, also it can be seen from the figure that a new peaks were appearedin the low energies, and have the values ( $(. \wedge 97) \mathrm{eV}$ for sample (b), $(1, \wedge \div)$ eV for samples(c and d), also it can be notice that the absorption coefficient increases with the increasing of $\mathrm{Fe}$ doping concentrationas mentioned in Table ( 1 ), such behavior could be attributed to the existence of more transitions from higher vibration levels of the ground state to higher sublevels of the first excited singlet state $[Y]$.

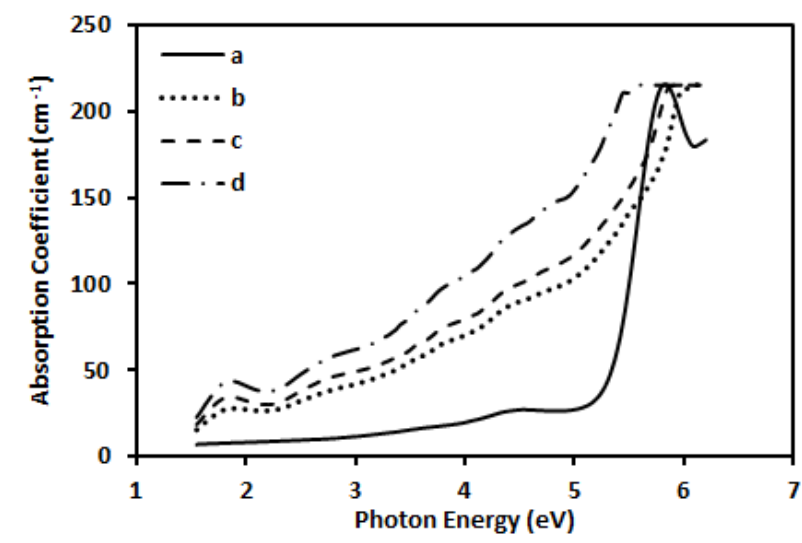

Fig. (') Variation of the absorption coefficient as a function of photon energy.

Table (')

Properties of PVA thin films for different concentrations at photon energy ( $r$, o $\mathrm{V}$ ).

\begin{tabular}{|c|c|c|c|c|c|c|c|c|}
\hline Samples & $M R(w t \%)$ & $\alpha\left(\mathrm{cm}^{-1}\right)$ & $R$ & $n$ & $K * 1,-\varepsilon$ & $\varepsilon r$ & $\varepsilon i$ & $\sigma(\Omega . c m)^{-1 * 1.11}$ \\
\hline $\mathbf{a}$ & . & $10,0 r$ & $1, \cdot 9$ & $1, \pi$ & $\cdot, \leqslant \mu$ & $1, \wedge v$ & $\cdot, \ldots, r$ &., 00 \\
\hline $\mathbf{b}$ & $\cdot, 0$ & $0 \leq, \vee q$ & $1 \wedge, \wedge 9$ & $Y, \cdot \varepsilon$ & $1,0 \leq$ & $\varepsilon, 17$ & +... & $\bar{T} Y, T V$ \\
\hline c & 1,0 & 71,99 & $19,7 V$ & $r, 9$ & $1, v \leq$ & $\varepsilon, \varepsilon$. &,$+ \ldots v r$ & $r, 1$. \\
\hline d & Pr & $\Delta 1,1 \mu$ & $r \cdot, r Y$ & $r, 10$ & $\overline{Y, Y \wedge}$ & $\varepsilon, 7 Y$ &,$+ \ldots 91$ & $\varepsilon, 17$ \\
\hline
\end{tabular}


Reflectance (R) of the films could be calculated using the following relation $\left[{ }^{1} \mathrm{r}\right]$ :-

$$
\mathrm{R}+\mathrm{T}+\mathrm{A}=1
$$

Where: T represent is the transmittance.

Plot of reflectance $R$ against photon energy are displayed in Fig. $(r)$. It is clear from the figure that the reflectance of the pure PVA film increases gradually with increasing of photon energy within the range $\left(1,00_{-}\right.$ $0, \varepsilon T) \mathrm{eV}$, this increasing indicate that the absorption is very low in region under energy gap, and decreasing the transmittance in this rang by the equation ( $r$ ). After doping the reflectance for all samples is increased in low photon energiesregion and moving the curves vertex for direction this energies, then it decreased in high energies before and after dopingdue to a decreasing in the energy gap with increasing impurity percentage $[\mathrm{I}]$.

The reflectance is increases with increasing impurity percentage as mentioned in Table ( 1 ), New peaks were appear in low energies $(1, \wedge 97) \mathrm{eV}$ for sample (b), (1,人7) $\mathrm{eV}$ for samples (c and d), which is an indication of change in the molecular structure degradation, polymer fragments, or free radicals of PVA and/or PVA/ Fe citrate films [ 1 ¿].

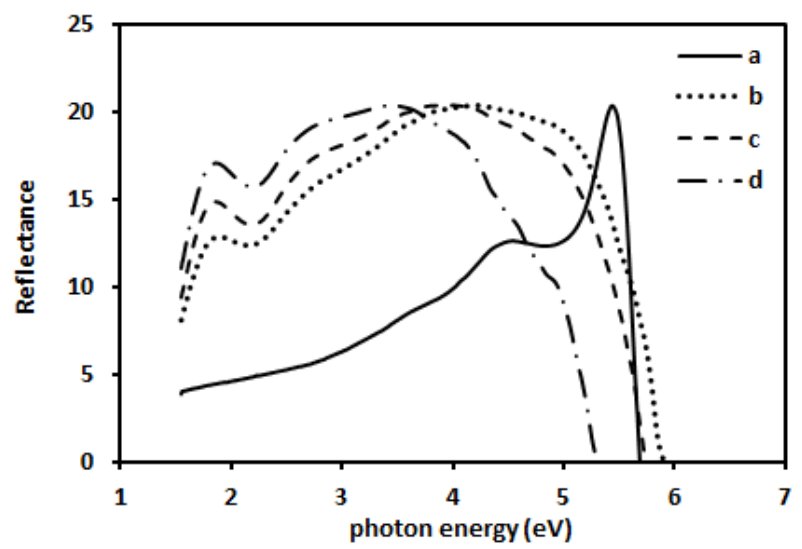

Fig. (') Reflection spectra as a function of photon energy of (a-d) PVA samples.

Refractive index $\mathrm{n}$ is one of the fundamental properties for an optical material because it is closely related to the electronic polarization of ions and the local field inside materials [10]. The complex optical constant (refractive index) of the prepared sampleshas been calculated from the $\mathrm{R}$ using the following relation $[17,1 \mathrm{~V}]$.
$\mathrm{n}=\left[(+\mathrm{R} / \mathrm{l}-\mathrm{R}]+\left[\varepsilon \mathrm{R} /(\backslash-\mathrm{R})^{r}-\mathrm{k}^{\Upsilon}\right]^{1 / \Gamma}\right.$

Fig.( $(\Gamma)$ : represent variation of the refractive index with photon energy for all films. In this figure the pure and doped PVA samples shows no different in curves between refractive index and reflectance because the refractive index depending on it. The refractive index were increases after doping in the low photon energies samples (b, c, and d), but it decreases in the high photon energy region and moving the curves vertex to low photon energies by increasing doping percentage, as well as new peaks were appear in low energies up to $(1, \wedge 97) \mathrm{eV}$ for sample (b), $(1, \wedge т) \mathrm{eV}$ for samples (c and d).The increase in refractive index with increasing of $\mathrm{Fe}$ concentration as noticed in Table (1) can be attributed to the increasing of the backing density as a result of filler content $[1 \wedge]$.

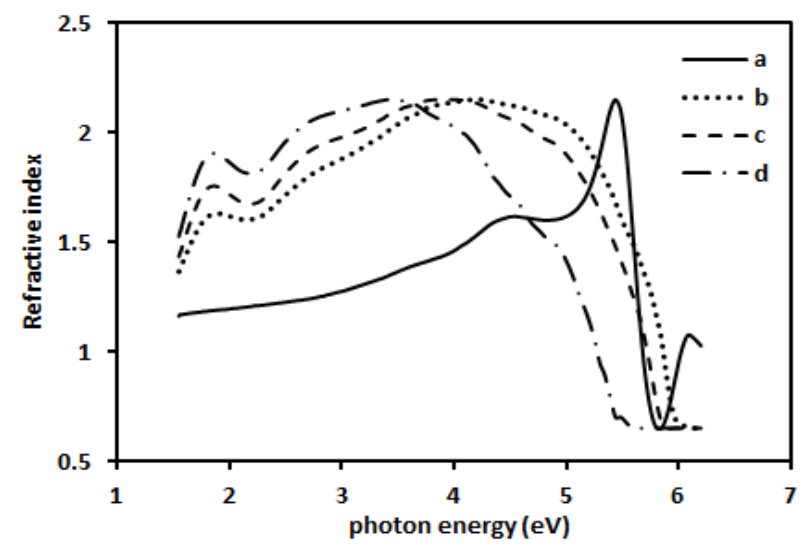

Fig. (') Variation of the refractive index as a function of photon energy.

Fig. ( $₹)$ : Shows the relation between extinction coefficient $\mathrm{k}$ as a function of photon energy for all films. One can observe that for the pure PVA sample extinction coefficient increases gradually with the increasing of photon energy within the range $\left(1,00_{-}, 0,17\right) \mathrm{eV}$ and hence high increase was happened in the beyond energies because of the operational absorption [19].

After adding impurity, formation of a new peaks were taken place $(1, \wedge) \wedge) \mathrm{eV}$ for samples (b, d) and $(\mathcal{l}, \wedge \mid \mathrm{r}) \mathrm{eV}$ for sample (c). The extinction coefficient increases with the increasing of photon energy for all samples and with increasing impurity concentration, Table (1). Such behavior was observed in the absorption coefficient, which means that the 
extinction coefficient is absorption coefficient related according to the following equation $[19, r \cdot]:-$

$$
\mathrm{k}=\frac{\alpha \lambda}{4 \pi}
$$

Where: $\lambda$ represent is the wavelength.

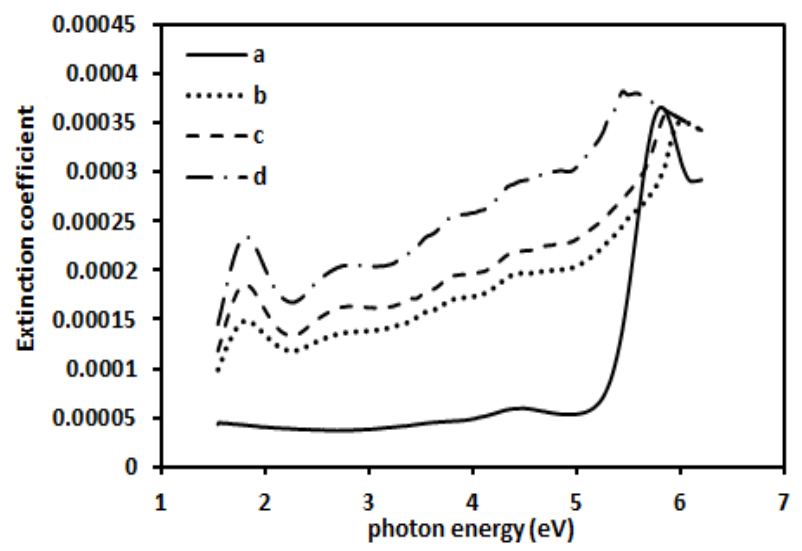

Fig. ( $)$ ) Variation of the extinction coefficient as a function of photon energy.

The real $\varepsilon_{\mathrm{r}}$ and imaginary $\varepsilon_{\mathrm{i}}$ parts of dielectric constant related to $(\mathrm{n})$ and $(\mathrm{k})$ values were calculated using the relations [ $r$ ) ]:-

$$
\begin{aligned}
& \varepsilon_{\mathrm{r}}=\mathrm{n}^{r}-\mathrm{k}^{r} \\
& \varepsilon_{\mathrm{i}}=r_{\mathrm{nk}} . . .
\end{aligned}
$$

The dependence of the real part on the photon energy is shown in Fig. ( $\left.{ }^{\circ}\right)$. It can be observed from this figure that the real part is depending on the refractive index according to equation $(0)$ because the extinction coefficient effect is very small and could beneglected [IT].

After doping the real part was increased with increasing impurity concentration, listed in Table (1), moving the curves vertex to low photon energies were happenedby increasing impurity percentage and a new peaks were appeared in the low photon energies $(1, \wedge 97) \mathrm{eV}$ for sample (b), $(1, \wedge \uparrow) \mathrm{eV}$ for samples (c and d) these resultsmay be attributed to relating real part of dielectric constant with refractive index $[1 \%]$.

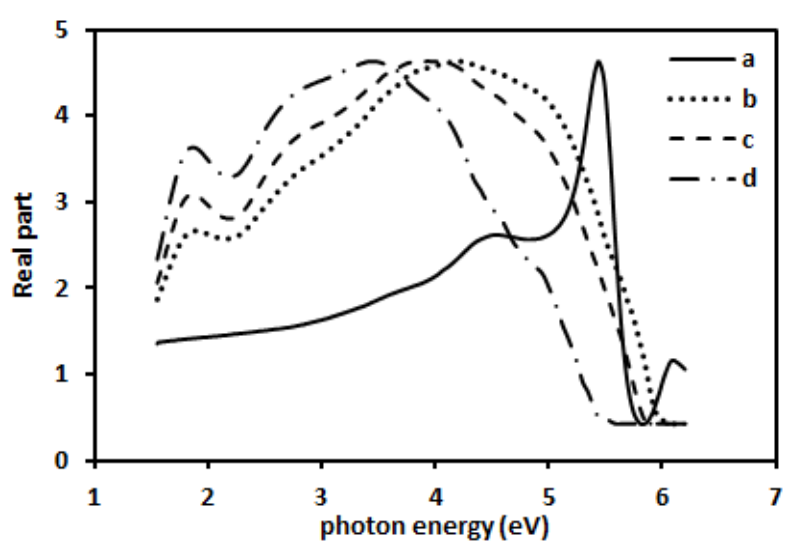

Fig. ( ()) Variation of the real part of dielectric constant as a function of photon energy.

The imaginary part of dielectric constant as a function of photon energy is shown in Fig. ( $(7)$. It is clear from this figure that the imaginary part depend onextinction coefficient according to equation ( 7 ) because the refractive index value is very small $[1, r, r r]$.

After doping with $\mathrm{Fe}$ the imaginary part of dielectric constant for the samples (b, c, and d) was increased with the increasing of photon energy and with increasing the doping concentration, Table ( 1$)$. New peaks were appear in photon energies up to $(1, \lambda \leqslant 0) \mathrm{eV}$ of sample (b), ( $1, \wedge r \mathrm{r}) \mathrm{eV}$ of (c) and $(1, \wedge \mathrm{r}) \mathrm{eV}$ of (d) which indicates that the samples have the no same structure. Hence, the change in the doping concentration gave change in the chemical composition of the polymer as referred by Abd El-Kader [ ${ }^{r}$ ]

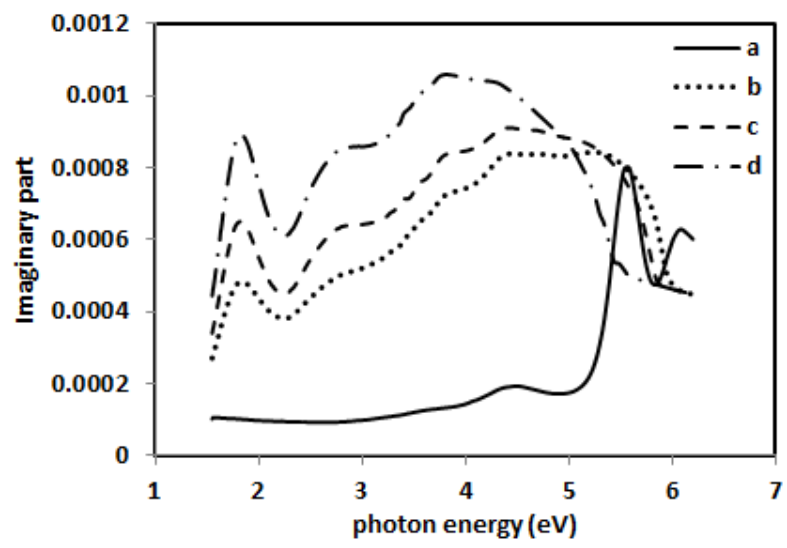

Fig. ( $)$ Variation of the imaginary part of dielectric constant as a function of photon energy.

According to the inter-band absorption theory, the optical band of the films can be calculated using Tauc's relation [ $r \leqslant]$ :-

$(\alpha h v)^{\mathrm{p}}=\mathrm{A}\left(\mathrm{hv}-\mathrm{E}_{\mathrm{g}}\right)$ 
Journal of Al-Nahrain University

Science

where $\alpha$ is the absorption coefficient, A a constant, $\mathrm{h}$ is Planck's constant, $v$ the photon frequency, $E_{g}$ the optical band gap and $p$ is an index which could take different values according to the electronic transition.

The experimental data were fitted to the theoretical Eq. $(\vee)$ for different values of $p$ and the best fit was obtained for $p=r$ this behavior directed that the transitions are allowed direct transitions. The direct allowed band gap was determined by plotting $(\alpha h v)^{r}$ as function of photon energy $E$ for samples ( $a, b, c$ and $d)$ is shown in Fig. $(\vee)$, the graph is a straight line and the value of $E_{g}$ is obtained by extrapolating the linear portion of the graph to intercept the photon energy axis [ $\left.{ }^{\circ}\right]$. It was found that $\mathrm{E}_{\mathrm{g}}$ reduces from $(0, \varepsilon \mathrm{VeV})$ of pure sample to $(0, r \uparrow, 0, r r, \varepsilon, \vee q) \mathrm{eV}$ for samples (b,c, d) respectively. Showing the values of direct allowed gap is mentioned in Table $(r)$. These values show that the presence of Fe leads to decrease in the optical energy gap for all samples according to the impurity concentration. The decrease in $\mathrm{E}_{\mathrm{g}}$ with increasing $\mathrm{Fe}$ concentration can be understood by considering the mobility gap variation in the doped polymer. Also the decrements of $\left(E_{g}\right)$ may be due to the transition between the molecular orbitals, which have highest occupied molecular orbitals instead of transition between valence-conduction band gap, polymers are usually amorphous insulators so one would consider the transition between the highest occupied molecular orbital and the lowest unoccupied molecular orbital instead of a valence-conduction band gap [ [ $r]$.

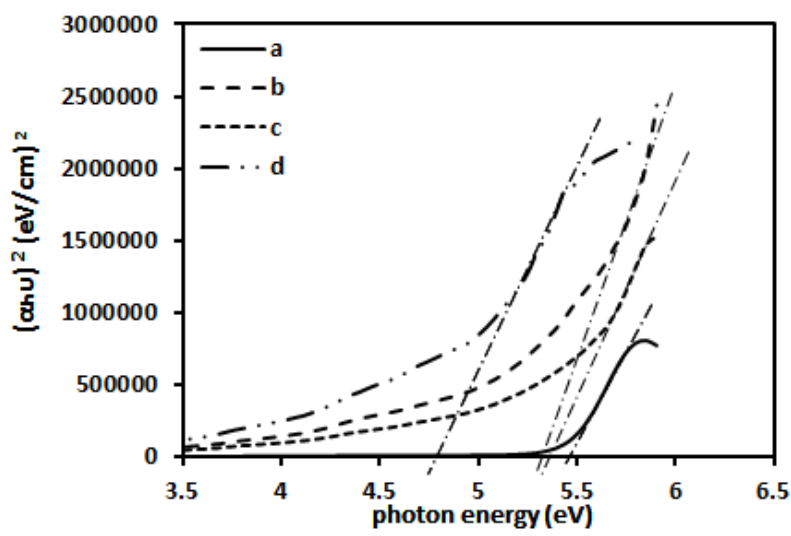

Fig. (V) Variation of (ahv) ${ }^{\gamma}(\mathrm{eV} / \mathrm{cm})^{\dagger}$ as a function of photon energy.
Vol. IV (\&), December, r.l\&, pp.q०_l.r

The width of the localized states available in the optical band gap affects the optical band gap structure and optical transitions and it is called as Urbach tail, which could be determined by the following equation $\left[{ }^{\mathrm{V}}\right]$ :

$$
\alpha=\alpha_{o} \exp \left(\frac{E}{\mathrm{Eu}}\right)
$$

Where $\alpha_{\mathrm{o}}$ is a constant and $\mathrm{E}_{\mathrm{u}}$ represent the Urbach energy which refers to the width of the exponential absorption edge.

The values of Urbach energy were calculated as the reciprocal gradient of the linear portion of the plot. Moreover, Fig. $(\wedge)$ shows the plot of $(\ln \alpha)$ versus photon energy $\mathrm{E}(\mathrm{eV})$ for all samples before and after doping. One can observe from this figure that the Urbach energy values were increased with the decreasing of energy gap and with the increasing of impurity concentrations, this behavior because the increase of defect levels in the allowed band gap by increasing $\mathrm{Fe}$ content $\left[{ }^{\top} \wedge\right]$. Table $(r)$ summarizes the values of $\mathrm{Eg}$ and $\mathrm{E}_{\mathrm{u}}$ for different concentration.

Table (r)

Properties of PVA thin films at different concentrations.

\begin{tabular}{|c|c|c|c|}
\hline Samples & $M R(w t \%)$ & $E g(e V)$ & $E u(e V)$ \\
\hline $\mathbf{a}$ & - & $0, \leqslant V$ & $\cdot, \leqslant 9$ \\
\hline b & $\cdot, 0$ & $0, r q$ & $\cdot, 0 \wedge$ \\
\hline c & 1,0 & $0, \mu r$ &., 09 \\
\hline d & $r$ & $\varepsilon, \sqrt{ } q$ & $\cdot, 71$ \\
\hline
\end{tabular}

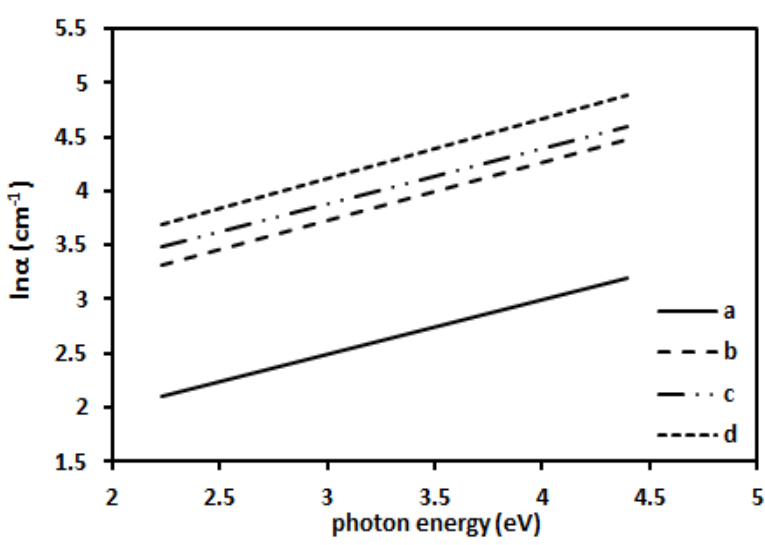

Fig. (1) Variation of (ln $\alpha)$ as a function of photon energy.

The optical conductivity was calculated using the relation $\left[r^{\top}\right]$ : 
$\sigma=\alpha \mathrm{nc} / \leqslant \pi$

Where $\sigma$ represent the optical conductivity, $\mathrm{c}$ is the velocity of light.

Fig. (9): represent the variation between optical conductivity $\sigma$ with the photon energy for all samples. The behavior of pure sample (a) is different from the doped samples (b, c, and d) where optical conductivity of it is slightly increases in low photon energies and then at higher photon energies it increases remarkably, while after doping the optical conductivity continue high increasing with increasing photon energy this behavior is resemble absorption coefficient because the depending on it.

Observe increasing in the optical conductivity with impurity concentrationas noticed in Table (1) causes to moving curves vertex to low photon energies and new peaks from energies $(1, \wedge 97) \mathrm{eV}$ for sample (b), $(1, \wedge \mathrm{)})$ $\mathrm{eV}$ for samples (c and d).

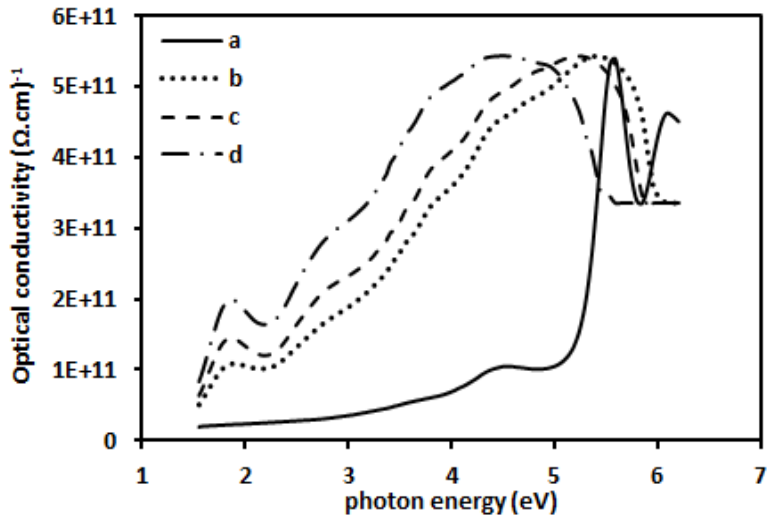

Fig. (9) Variation of the optical conductivity as a function of photon energy.

\section{Conclusion}

In this work, the effect of $\mathrm{Fe}$ citrate impurity on the optical properties of PVA films has been studied, where the optical constants such as absorption coefficient, refractive index, extinction coefficient, real and imaginary parts of dielectric constant Urbach energyand optical conductivity were investigated. Results show that the optical constants of the pure PVA films were increased after doping and with increasing impurity concentration. Moreover the values of energy gap were decreased after doping and with increasing impurity concentration. No same structure was appearing of sampleshence, the change in the doped percentage gave change in the chemical composition of the polymer.

\section{Reference}

['] Vorcik, V; Lyutakov, O; Huttel, I.; "Thickness dependence of refractive index and optical gap of PMMA layers prepared under electrical field"; Mater Electron. 19, rTr_rTV, Y..人.

[ץ] Abdullah, O. G.; Saber, D. R.; "Optical absorption of Poly (vinyl Alcohol) films Doped with Nickel Chloride"; Applied Mechanics and Materials. 11.-117, 11V. IAr, $r \cdot \mid r$.

[ץ] Tagreed, K.H.; "Refrectiv index dispesion and analysis of the optical parameters of (PMMA/PVA) thin film"; Journal of al-Nahrain University. $17(r), \quad 17 \varepsilon_{-} / \mathrm{V} \cdot$ $r+1 r$.

[₹] Hirankumar, G.; Selvasekarapandian, S.; Kuwata, N.; Kawamura, J.; Hattori, T.; "Thermal, electrical and optical studies on the poly(vinyl alcohol) based polymer electrolytes"; Journal of Power Sources. I $\leqslant \varepsilon$, YTY_Y YV, Y..O.

[०] Saion, E.; Susilawati; Doyan, A.; Zainal Abdinal, S.; Azmi, Z.; Zulkfli, A.; Mohad Zaki, A.R.; Dahlan, K.Z.H.; Karni, T.; "Changes in the optical band gap and absorption edge of gamma-irradiation polymer blends"; Journal of Applied Sciences. ${ }^{\circ}(1 \cdot), 1 \wedge r o_{-} \wedge \wedge q, r \ldots o$.

[7] Chandrakala, H. N.; Ramaraj, B.; Shivakumaraiah; Madhu G.M.; Siddaramaiah; "Investigation on the influence of sodiumzirconatenanoparticles on the structural characteristics and electrical properties of polyvinyl alcohol Nanocomposite films";journal of alloys and compounds. 000, or l_ors, r. 1 r.

[У] Vashistha, P.; Gaur, S.S., Tripathi, K.N.; "Characterization of ammonium dichromate doped PVA films based waveguides"; Opt

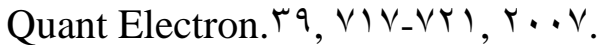

[^] Sharma, A. K.; Ramu, C. H.; "Optical properties of pure and iron-doped cellulose"; Journal of Materials Sciences letters. $1 \cdot(r \cdot),|r| V_{-}|r| 9,1991$.

[9] Obreja, P., Kusko, M., Cristea, D., Purica, M., Comanescu, F.; "Doped polymers controllable indexe-preparation, processing 
Journal of Al-Nahrain University

Science

and applications"; Proceedings of the symposium on photonics Technologies for $v^{\text {th }}$ Framework program. $\left|r_{-}\right| \leqslant, r_{9} r_{-} r_{90}$, r....

[1·] Han, X.; Liu, R.; Chen, W.; Xu, Z.; "Properties of nanocrystalline zinc oxide thin films prepared by thermal decomposition of electrodeposited zinc peroxide"; Thin Solid Films. $017, \varepsilon \cdot r 0_{-} \varepsilon \cdot r q, r \cdots \wedge$.

[1'] Abd El-Kader, K.A.M.; Abdel Hamied, S.F.; Mansour, A.B.; EL-Lawindy; ELTantaway, F.;" Effect of the molecular weights on the optical and mechanical properties of poly(vinyl alcohol) films"; polymer Testing. $r$, $, \wedge \leqslant V_{-} \wedge 0_{0}, r \cdots r$.

[I $]$ Ahmed, R.M.; "Optical study on poly (methyl methacrylate)/ poly (vinyl acetate) blends"; International Journal of photoenergy. Volume $Y . .9$, Article ID 10.r^q, $V$ pages, r.. 9 .

[1T] Khadum, K.A.: "Study of optical constant for cadmium oxide films doped with silver oxide (CdO: $\mathrm{AgO})$ in infrared region; Diala, Jour. ${ }^{r}$, $1-10, r \ldots 9$.

[ 1 [ Z Zahr El-Deen, H.; Hafez, A.I.; "Physicschemical stability of PVA films doped with $\mathrm{Mn}^{+r}$ ions against weathering conditions"; The Arabian Journal for science and engineering. $r \leqslant(\backslash A), 1 r-r \tau, r \ldots q$.

[10] Bakry, A.M.; Mahmoud, S.A.; "Effect of substrate temperature on the optical dispersion of sprayed Nickel oxide thin films"; Journal of Saudi International Electronics, Communications and Photonics Conference (SIECPC). published by IEEE. . $\checkmark, Y \cdot l l$.

[ 17 ] Islam, M. R.; Podder; "Optical properties of $\mathrm{ZnOnano}$ fiber thin films grown by spray pyrolysis of zinc acetate precursor";

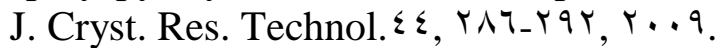

[ $\mathrm{V}$ ] Atyia, H. E.; "Influence of deposition temperature on the structural and optical properties of InSbSer films"; Optoelectron.

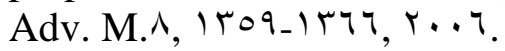

['^] Wasan, Al-Taa'y; Mohammed A.N.; Rahimi, M.Y.; Emad, Y., Bashar, M.A., Jumat, S., Nadia, S.; Saiful, I.Z.; "Effect of nanoZnO on the optical properties of poly (vinyl chloride) films"; International journal of polymer science. Volume $r, \mathcal{\text { I }}$, article ID $79 \vee \cdots 9,7$ pages, $Y \cdot 1 \leqslant$.

[19] Naimi, A.A.; Zubaidi, M.F.; "Studying the Optical Properties Cadmium Stunet

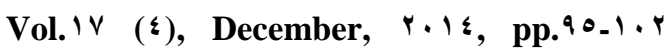

$\mathrm{Cd}^{\Upsilon} \mathrm{SnO} \leqslant$ Thin Films Prepared by Spray Pyrolysis Technique"; Eng\& Technology. $r V(1 \leqslant), \leqslant \leqslant 0_{-} \leqslant 07, r \ldots q$.

$[ץ \cdot]$ Fox, M.; "Optical Properties of Solid. Great Britain"; Oxford university; New York. USA; $r \cdots$.

[r)] Ezema, E.I.; Asogwa, P.U.; Ekwealor, P.E.; Ugwuoke, P.E.; Osuji, R.U.;"Growth and optical properties of $\mathrm{Ag}_{\uparrow} \mathrm{S}$ thin films deposition technique"; Journal of the university of chemical technology and metallurgy. $\left\{r(r), r \mid V_{-} r r r, r \cdots V\right.$.

$\left[r^{r}\right]$ Ahmad, A. H.; Awatif, A. M.; Zeid, Abdul-Majied. N.; "Doppin effect on optical constants of polymethylmethacrylate (PMMA)"; Eng \& Technology. ro( $)$ ), $00 \Lambda_{\text {_ }}$ OTA, Y.. Y.

[rr] Abd El-Kader, K. M.; Orabi, A. S.; "Spectroscopic behavior of poly (vinyl alcohol) films with different molecular weights"; polymer Testing. ${ }^{Y}$, 091-090, r. . r.

[Y $\left.{ }^{Y}\right]$ Prabahar, S.; Balasubramanian, V.; Suryanarayanan, N.; Muthukumarasamy, N.; "Optical properties of copper indium diselenide thin films"; Chalcogenide

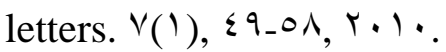

[ro] Prabahar, S.; Balasubramanian, V.; Suryanarayanan, N.; Muthukumarasamy, $\mathrm{N}$;; "Optical properties of copper indium diselenide thin films; Chalcogenide letters. $Y(1)$, , $9.0 \wedge, r \cdot 1$.

[Yฯ] Zahr El-Deen. H and Hafez.A.I. Y.. 9 . Physics-chemical stability of PVA films doped with $\mathrm{Mn}^{+r}$ ions against weathering conditions, The Arabian Journal for scienceand engineering, $r \varepsilon(\mathcal{A})$ : I T_r .

[rV] Caglar, Y.; Ilican, S.; Caglar, M.; Yakuphanoglu, F.; "effects of In, Al and optical absorption in amorphous silicon and amorphous germanium"; journal of Noncrystalline solids. $r 1 \cdot 9 r_{-} r, r \leq 9,199 v$.

[ ${ }^{\wedge} \wedge$ ] El-Bashir, S. M.; "photophysical properties of florenscent $\mathrm{PMMA} / \mathrm{SiO}$ r nanohybridsfor solar energy appl-ications"; Journal of Luminescence. Irr, IVAr_IVq|, r.Ir.

[ ${ }^{9}$ ] Pankove, J. I.; "Optical processes in semiconductors", Dover Publications, Inc. New York, १1; $19 \vee 0$. 
الخلاصة

حضرت أغشية PVA و PVA المشوبه بسترات الحديد

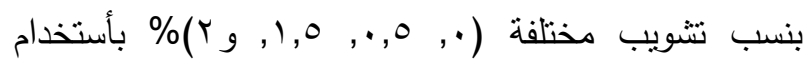
طريقة الصب. تم دراسة الخواص البصريه للأغشيه حيث سجل طيفي النفاذيه والامتصاصيه في مدى الاطوال الموجيه

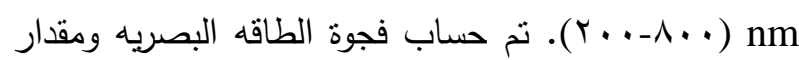

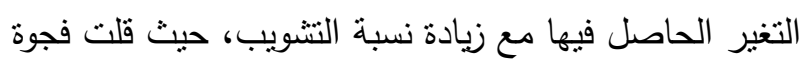
الطاقه

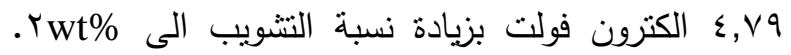

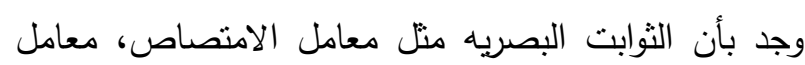

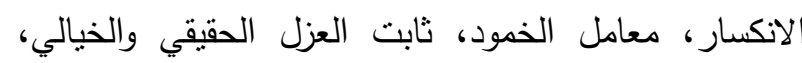
التوصيليه البصريه جميعها تأثرت بالتشويب حيث أظهرت التكارت الترل النتائج أن الثوابت البصريه تزداد بزيادة نسبة التشويب. طاقة

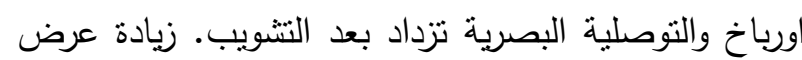

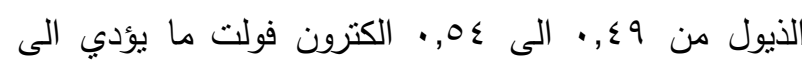

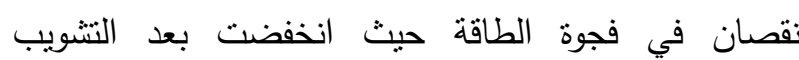
بالاضافة الى انخفاضها مع زيادة هذه النسب. 